\title{
Efficiency assessment using a multidirectional DDF approach
}

\author{
Sebastián Lozano ${ }^{\mathrm{a} \S}$ and Narges Soltani ${ }^{\mathrm{b}}$ \\ ${ }^{a}$ Dept. of Industrial Management, University of Seville, Spain \\ ${ }^{\mathrm{b}}$ Department of Mathematics, Kharazmi University, Tehran, Iran
}

INTERNATIONAL TRANSACTION IN OP. RESEARCH, 27 (2020) 2064-2080

Doi: 10.111 itor.12617

\begin{abstract}
This paper proposes a new efficiency measure that aims at capturing the overall distance to the efficient frontier and not the distance corresponding to a specific projection, as most oriented and non-oriented methods compute. The proposed approach uses a grid-based method to sample all possible improvement directions from a given operating point and for each direction it computes a directional efficiency score solving a directional distance function (DDF) model. This provides information about the distribution of the distance to the efficient frontier. Therefore, the proposed Multidirectional Efficiency Measure (MEM) does not provide a single efficiency score but a distribution of efficiency scores. The minimum, the median, the Q1 and Q3 quartiles and the maximum can be singled out as representatives of that distribution. The latter corresponds to the closest among the computed efficient targets. In addition to the efficiency score distribution, the associated efficient targets are also provided. The proposed approach can take into account integer and non-discretionary variables and a preference structure. An application of the method to assess the efficiency of material recovery facilities is presented.
\end{abstract}

Keywords: DEA; multidirectional efficiency measure; directional vectors sampling; directional efficiency score distribution; material recovery facilities

$\S \quad$ Corresponding author:

Escuela Superior de Ingenieros

Camino de los Descubrimientos, s/n, 41092 Sevilla, Spain

(Phone: +34-954487208 E-mail: slozano@us.es) 


\section{Introduction}

Efficient operation is key for the competitiveness of businesses and for sustainable development overall. The most useful methodology for assessing the relative efficiency of a set of similar productive or organizational entities is Data Envelopment Analysis (DEA). The units being benchmarked are usually termed Decision Making Units (DMUs) and they consume different inputs in order to produce different outputs. From the amount of inputs consumed and outputs produced by each DMU and using some basic assumptions (such as envelopment of the observed data, free disposability and convexity) an appropriate Production Possibility Set (PPS), which contains all feasible operating points, is inferred (see, for example, Cooper et al. 2006). If it is possible for a DMU to increase its outputs without increasing its inputs or to reduce its inputs consumption without reducing its outputs, then it is inefficient. Not only can DEA determine if a DMU is efficient or not but it can also measure the extent of the inefficiency and the potential improvements (i.e. input reductions and output increases) that can be achieved. Moreover, because of its non-parametric character, DEA has wide applicability. Thus, for example, it has been applied to manufacturing firms (e.g. Huang 2018), public services (e.g. Moreno and Lozano 2018), universities (e.g. Tran and Villano 2018), banks (e.g. Chen et al. 2017), accounting firms (e.g. Hsiao et al. 2017), airports (e.g. Yu and Hsiao 2018), etc.

The DEA methodology involves solving, for each DMU in turn, an appropriate model that projects it onto the efficient frontier, which is the non-dominated subset of the PPS and contains the operating points that represent the best practices. The efficiency of a DMU is related to how far it is from the efficient frontier. This DEA projection can be done using different DEA models. The most well-known DEA models are the radial oriented CCR and BCC models of Charnes et al. (1978) and Banker et al. (1984), respectively. Some other well-known DEA models are the hyperbolic index (Färe et al. 1985), the Färe-Grosskopf-Lovell index (Färe et al. 1985), the weighted additive efficiency index (Charnes et al. 1985) and the Directional Distance Function (DDF, Chambers et al. 1996). And there are also the Enhanced Russell Graph Measure (ERGM) of Pastor et al. (1999) (a.k.a. Slacks-Based Measure, SBM, Tone 2001), the Potential Improvements approach of Bogetoft and Hougaard (1999) (later relabeled Multi-directional Efficiency Analysis, MEA, in Asmild et al. 2003), the Range Directional Measure (RDM) of Silva Portela et al. (2004), the Bounded Adjusted Measure (BAM) of Cooper et al. (2011), etc. 
Given the large number of existing DEA methods, carrying out a survey of DEA efficiency indexes is out of the scope of this paper as it is also a theoretical or empirical comparison between them. Trying to distinguish between the different inefficiency indexes, some studies, like Russell and Schworm (2009, 2011), have studied some basic properties, like indication of efficiency, monotonicity, units independence and continuity. Although these studies have helped to understand better and differentiate between them, the fact remains that there are many different efficiency indexes in DEA and that they generally lead to different efficiency measurements. Although this enriches the efficiency assessment field and is a sign of how active this research field is, it can also be confusing for the practitioner, who may wonder which of these methods provides the right efficiency score in general or for a specific application.

In our view, there are situations in which a DMU has a clear idea of the projection direction it wishes and, in those cases, the conventional approach that maximizes the improvements in that direction until an efficient target is reached is appropriate. However, it may also happen that the DMU has not a fixed idea about which of the possible improving directions to follow. In that case, it makes sense for the DMU to explore different possibilities and determine the corresponding maximum amount of improvement (i.e. how far the efficient frontier is) in that projection direction. We believe that, with that information, the DMU is in a better position to assess its overall efficiency status as well as to decide which way to go.

Moreover, since the efficiency measure depends on the projection direction chosen, it follows that efficiency is a multi-valued function and not a single number. So, instead of providing an efficiency score, associated to a specific benchmark selection, we propose to determine, by appropriate sampling, the distribution of the efficiency along all possible projection directions. Thus, using a simple LP optimization model and investing some computational effort, we can draw a better picture of the efficiency improving possibilities of a DMU and thus more effectively assess its overall efficiency status.

The Multidirectional Efficiency Measure (MEM) proposed in this paper uses a grid-based method that generates uniformly-spread improving directions, determining the distribution of the efficiency score (i.e. the distance to the efficient frontier) along all those improving directions. This is different from the usual approach of computing a single figure to gauge the efficiency of 
a DMU by comparison with a reference efficient target computed using a certain projection direction or criterion. Therefore, the proposed Mutidirectional Efficiency Measure is not a single figure but a distribution of efficiency scores and thus provides a more comprehensive assessment of the distance of the DMU to the efficient frontier.

A somewhat related approach is the use of hypervolumes to measure technological possibilities, as suggested in Asmild and Hougaard (2016), where the computation of the hypervolumes can be done using specific algorithms or, for the Free Disposal Hull (FDH) case, using Monte Carlo sampling. That approach differs from ours in several respects. The main one is that it aims at computing a hypervolume index for the whole sample of DMUs while we aim at estimating the efficiency of each DMU. Actually, Asmild and Hougaard (2016) compute the efficiency of the DMUs in a conventional way, i.e. providing a single score.

The structure of the paper is the following. Section 2 presents the proposed MEM approach, which is illustrated in Section 3 using a simple numerical example. Section 4 applies the proposed approach to assess the efficiency of material recovery facilities. Finally, Section 5 summarizes and concludes.

\section{Proposed MEM approach}

When a DMU is inefficient there are many ways of removing the inefficiencies. Depending on the specific way chosen (i.e. the projection direction) the amount of improvement possible is larger or smaller. That is what the corresponding directional efficiency score measures. The idea behind the proposed Multidirectional Efficiency Measure is to estimate the distribution of those directional efficiency scores for the whole set of improving directions. This gives a more complete information about the whole set of improvement possibilities available to the DMU, much richer than providing a single figure for the efficiency score based on a single efficient target. In addition, it does not require that the analyst chooses the projection direction ex ante. This gives much greater flexibility and allows choosing the projection direction ex post.

Formulating the basic DDF model that is at the heart of the proposed MEM approach will require introducing some notation. Let 
$\mathrm{j}=1,2, \ldots, \mathrm{n} \quad$ index on DMUs

0 index of a certain DMU whose efficiency is to be determined

$\mathrm{i}=1,2, \ldots, \mathrm{m} \quad$ index on inputs

$\mathrm{k}=1,2, \ldots, \mathrm{s} \quad$ index on outputs

$\mathrm{x}_{\mathrm{ij}} \quad$ amount of input $\mathrm{i}$ consumed by DMU $\mathrm{j}$

$\mathrm{y}_{\mathrm{kj}} \quad$ amount of output $\mathrm{k}$ produced by DMU $\mathrm{j}$

Let us assume that some inputs $\mathrm{i} \in \mathrm{I}^{\mathrm{int}}$ and outputs $\mathrm{k} \in \mathrm{O}^{\text {int }}$ can only take integer values and that all inputs and outputs are strictly positive. Assuming Variable Returns to Scale (VRS), the corresponding PPS (see Lozano and Villa 2006, Kuosmanen and Kazemi Matin 2009, Kazemi Matin and Kuosmanen 2009) is the following

$$
\begin{aligned}
\mathrm{T}^{\mathrm{VRS}}=\left\{(\mathrm{x}, \mathrm{y}) \in \mathfrak{R}_{+}^{\mathrm{m}+\mathrm{s}} \mid \exists \lambda \geq 0 \quad \sum_{\mathrm{j}=1}^{\mathrm{n}} \lambda_{\mathrm{j}} \mathrm{x}_{\mathrm{ij}} \leq \mathrm{x}_{\mathrm{i}} \forall \mathrm{i} \quad \mathrm{x}_{\mathrm{i}} \text { integer } \forall \mathrm{i} \in \mathrm{I}^{\mathrm{int}}\right. \\
\left.\sum_{\mathrm{j}=1}^{\mathrm{n}} \lambda_{\mathrm{j}} \mathrm{y}_{\mathrm{kj}} \geq \mathrm{y}_{\mathrm{k}} \forall \mathrm{k} \quad \mathrm{y}_{\mathrm{k}} \text { integer } \forall \mathrm{k} \in \mathrm{O}^{\mathrm{int}} \quad \sum_{\mathrm{j}=1}^{\mathrm{n}} \lambda_{\mathrm{j}}=1\right\}
\end{aligned}
$$

where $\mathfrak{R}_{+}^{\mathrm{m}+\mathrm{s}}$ is the non-negative quadrant of the real vector space of dimension $\mathrm{m}+\mathrm{s}$.

The DDF approach projects DMU 0 along a direction given by a directional vector $\mathrm{g}=\left(\mathrm{g}^{\mathrm{x}}, \mathrm{g}^{\mathrm{y}}\right) \in \mathfrak{R}_{+}^{\mathrm{m}+\mathrm{s}}$. The corresponding DDF (which is an inefficiency score) corresponds to the maximum stepsize from $\left(\mathrm{x}_{0}, \mathrm{y}_{0}\right)$ along direction $\left(-\mathrm{g}^{\mathrm{x}}, \mathrm{g}^{\mathrm{y}}\right)$ (Chambers et al. 1996). Since the conventional DDF model may compute a weak efficient target it is convenient to consider a phase II that maximizes the sum of the normalized input and output slacks. The best way to do this is using a lexicographic optimization approach. Alternatively, although in that case care must be taken to select a sufficiently small value for the non-Archimedean infinitesimal $\varepsilon$ (see, e.g., Podinovski and Bouzdine-Chameeva 2017), both phases can be integrated in a single linear program (LP) as 
$\underset{\lambda, \beta, \mathrm{s}^{\mathrm{x}}, \mathrm{s}^{\mathrm{y}}, \hat{\mathrm{x}}, \hat{\mathrm{y}}}{\operatorname{Max}} \beta+\varepsilon \cdot\left(\sum_{\mathrm{i}} \frac{\mathrm{s}_{\mathrm{i}}^{\mathrm{x}}}{\mathrm{x}_{\mathrm{i} 0}}+\sum_{\mathrm{k}} \frac{\mathrm{s}_{\mathrm{k}}^{\mathrm{y}}}{\mathrm{y}_{\mathrm{k} 0}}\right)$

s.t.

$\sum_{\mathrm{j}} \lambda_{\mathrm{j}} \mathrm{x}_{\mathrm{ij}} \leq \hat{\mathrm{x}}_{\mathrm{i}}=\mathrm{x}_{\mathrm{i} 0}-\beta \cdot \mathrm{g}_{\mathrm{i}}^{\mathrm{x}}-\mathrm{s}_{\mathrm{i}}^{\mathrm{x}} \quad \forall \mathrm{i}$

$\sum_{\mathrm{j}} \lambda_{\mathrm{j}} \mathrm{y}_{\mathrm{kj}} \geq \hat{\mathrm{y}}_{\mathrm{k}}=\mathrm{y}_{\mathrm{k} 0}+\beta \cdot \mathrm{g}_{\mathrm{k}}^{\mathrm{y}}+\mathrm{s}_{\mathrm{k}}^{\mathrm{y}} \quad \forall \mathrm{k}$

$\sum_{j} \lambda_{j}=1$

$\lambda_{\mathrm{j}} \geq 0 \forall \mathrm{j} \quad \beta$ free $\quad \mathrm{s}_{\mathrm{i}}^{\mathrm{x}} \geq 0 \forall \mathrm{i} \quad \mathrm{s}_{\mathrm{k}}^{\mathrm{y}} \geq 0 \forall \mathrm{k}$

$\hat{\mathrm{x}}_{\mathrm{i}} \geq 0 \quad \forall \mathrm{i} \quad \hat{\mathrm{x}}_{\mathrm{i}}$ integer $\forall \mathrm{i} \in \mathrm{I}^{\text {int }}$

$\hat{\mathrm{y}}_{\mathrm{k}} \geq 0 \quad \forall \mathrm{k} \quad \hat{\mathrm{y}}_{\mathrm{k}}$ integer $\forall \mathrm{k} \in \mathrm{O}^{\mathrm{int}}$

The corresponding directional target is

$$
\hat{x}_{\mathrm{i}}\left(\mathrm{g}^{\mathrm{x}}, \mathrm{g}^{\mathrm{y}}\right)=\mathrm{x}_{\mathrm{i} 0}-\beta^{*} \cdot \mathrm{g}_{\mathrm{i}}^{\mathrm{x}}-\left(\mathrm{s}_{\mathrm{i}}^{\mathrm{x}}\right)^{*} \quad \forall \mathrm{i} \quad \hat{\mathrm{y}}_{\mathrm{k}}\left(\mathrm{g}^{\mathrm{x}}, \mathrm{g}^{\mathrm{y}}\right)=\mathrm{y}_{\mathrm{k} 0}+\beta^{*} \cdot \mathrm{g}_{\mathrm{k}}^{\mathrm{y}}+\left(\mathrm{s}_{\mathrm{k}}^{\mathrm{y}}\right)^{*} \quad \forall \mathrm{k}
$$

where the notation used emphasizes that the target depends on the directional vector $\mathrm{g}=\left(\mathrm{g}^{\mathrm{x}}, \mathrm{g}^{\mathrm{y}}\right)$. Hence, a directional efficiency score can be computed as

$$
\eta_{0}\left(g^{\mathrm{x}}, g^{\mathrm{y}}\right)=\frac{\frac{1}{\mathrm{~m}} \sum_{\mathrm{i}} \frac{\hat{\mathrm{x}}_{\mathrm{i}}\left(\mathrm{g}^{\mathrm{x}}, \mathrm{g}^{\mathrm{y}}\right)}{\mathrm{x}_{\mathrm{i} 0}}}{\frac{1}{\mathrm{~s}} \sum_{\mathrm{k}} \frac{\hat{\mathrm{y}}_{\mathrm{k}}\left(\mathrm{g}^{\mathrm{x}}, \mathrm{g}^{\mathrm{y}}\right)}{\mathrm{y}_{\mathrm{k} 0}}}=\frac{1-\frac{1}{\mathrm{~m}} \sum_{\mathrm{i}} \frac{\mathrm{x}_{\mathrm{i} 0}-\hat{\mathrm{x}}_{\mathrm{i}}\left(\mathrm{g}^{\mathrm{x}}, \mathrm{g}^{\mathrm{y}}\right)}{\mathrm{x}_{\mathrm{i} 0}}}{1+\frac{1}{\mathrm{~s}} \sum_{\mathrm{k}} \frac{\hat{\mathrm{y}}_{\mathrm{k}}\left(\mathrm{g}^{\mathrm{x}}, \mathrm{g}^{\mathrm{y}}\right)-\mathrm{y}_{\mathrm{k} 0}}{\mathrm{y}_{\mathrm{k} 0}}}
$$

Note that this way of measuring the distance between DMU 0 and its directional target is analogous to the one used in ERGM and SBM. Actually, the ERGM/SBM efficiency score can be obtained substituting the objective function of model (2) by 


$$
\xi_{0}^{\mathrm{SBM}}=\operatorname{Min} \frac{1-\frac{1}{\mathrm{~m}} \sum_{\mathrm{i}} \frac{\mathrm{x}_{\mathrm{i} 0}-\hat{\mathrm{x}}_{\mathrm{i}}}{\mathrm{x}_{\mathrm{i} 0}}}{1+\frac{1}{\mathrm{~s}} \sum_{\mathrm{k}} \frac{\hat{\mathrm{y}}_{\mathrm{k}}-\mathrm{y}_{\mathrm{k} 0}}{\mathrm{y}_{\mathrm{k} 0}}}
$$

The difference between (4) and (5) is that while the target used to compute $\eta_{0}\left(\mathrm{~g}^{\mathrm{x}}, \mathrm{g}^{\mathrm{y}}\right)$ uses a given directional vector, the one computed by $\xi_{0}^{\mathrm{SBM}}$ can be freely chosen among those that dominate the DMU 0. Therefore, the directional efficiency score $\eta_{0}\left(g^{\mathrm{x}}, \mathrm{g}^{\mathrm{y}}\right)$ is never lower than $\xi_{0}^{\mathrm{SBM}}$. Actually, $\xi_{0}^{\mathrm{SBM}}=\underset{\left(\mathrm{g}^{\mathrm{x}}, \mathrm{g}^{\mathrm{y}}\right) \geq 0}{\operatorname{Min}} \eta_{0}\left(\mathrm{~g}^{\mathrm{x}}, \mathrm{g}^{\mathrm{y}}\right)$ and hence coincides with $\eta_{0}\left(\mathrm{~g}^{\mathrm{x}}, \mathrm{g}^{\mathrm{y}}\right)$ for a certain projection direction.

The proposed MEM approach solves the DDF model (2) for multiple directional vectors. Those directional vectors are generated using normalized vectors $\alpha=\left(\alpha^{\mathrm{x}}, \alpha^{\mathrm{y}}\right)$ belonging to the unit simplex

$$
\left\{\left(\alpha^{\mathrm{x}}, \alpha^{\mathrm{y}}\right) \in \mathfrak{R}_{+}^{\mathrm{m}+\mathrm{s}}: \sum_{\mathrm{i}} \alpha_{\mathrm{i}}^{\mathrm{x}}+\sum_{\mathrm{k}} \alpha_{\mathrm{k}}^{\mathrm{y}}=1\right\}
$$

and located in a grid of size $\Delta$, i.e. $\quad \alpha_{1}^{\mathrm{x}}=0, \Delta, 2 \Delta, \ldots, 1, \quad \alpha_{2}^{\mathrm{x}}=0, \Delta, 2 \Delta, \ldots, 1-\alpha_{1}^{\mathrm{x}}$, $\alpha_{3}^{\mathrm{x}}=0, \Delta, 2 \Delta, \ldots, 1-\alpha_{1}^{\mathrm{x}}-\alpha_{2}^{\mathrm{x}}, \ldots$

In order for MEM to be units invariant, the directional vectors are generated using

$$
\begin{aligned}
& \mathrm{g}_{\mathrm{i}}^{\mathrm{x}}=\alpha_{\mathrm{i}}^{\mathrm{x}} \cdot \mathrm{R}_{\mathrm{i} 0}^{\mathrm{x}} \quad \forall \mathrm{i} \\
& \mathrm{g}_{\mathrm{k}}^{\mathrm{y}}=\alpha_{\mathrm{k}}^{\mathrm{y}} \cdot \mathrm{R}_{\mathrm{k} 0}^{\mathrm{y}} \quad \forall \mathrm{k}
\end{aligned}
$$

where $\mathrm{R}_{0 \mathrm{i}}^{\mathrm{x}}$ and $\mathrm{R}_{0 \mathrm{k}}^{\mathrm{y}}$ are the maximum potential improvement for DMU 0 along each input and output dimension, respectively. These maximum potential improvements can be computed as 


$$
\begin{aligned}
& \mathrm{R}_{\mathrm{i} 0}^{\mathrm{x}}=\mathrm{x}_{\mathrm{i} 0}-\mathrm{x}_{\mathrm{i} 0}^{\min } \quad \forall \mathrm{i} \\
& \mathrm{R}_{\mathrm{k} 0}^{\mathrm{y}}=\mathrm{y}_{\mathrm{k} 0}^{\max }-\mathrm{y}_{\mathrm{k} 0} \quad \forall \mathrm{k}
\end{aligned}
$$

where

$$
\mathrm{x}_{\mathrm{i} 0}^{\min }=\underset{\lambda, \mathrm{x}_{\mathrm{i}}}{\operatorname{Min}} \mathrm{x}_{\mathrm{i}}
$$

s.t.

$\sum_{j} \lambda_{j} x_{i^{\prime} j} \leq x_{i^{\prime} 0} \quad \forall i^{\prime} \neq i$

$\sum_{j} \lambda_{j} x_{i j} \leq x_{i}$

$\sum_{\mathrm{j}} \lambda_{\mathrm{j}} \mathrm{y}_{\mathrm{kj}} \geq \mathrm{y}_{\mathrm{k} 0} \quad \forall \mathrm{k}$

$\sum_{j} \lambda_{j}=1$

$\lambda_{\mathrm{j}} \geq 0 \forall \mathrm{j}$

$\mathrm{x}_{\mathrm{i}} \geq 0 \quad\left(\mathrm{x}_{\mathrm{i}}\right.$ integer if $\left.\mathrm{i} \in \mathrm{I}^{\mathrm{int}}\right)$

$\mathrm{y}_{\mathrm{k} 0}^{\max }=\underset{\lambda, \mathrm{y}_{\mathrm{k}}}{\operatorname{Max}} \mathrm{y}_{\mathrm{k}}$

s.t.

$\sum_{\mathrm{j}} \lambda_{\mathrm{j}} \mathrm{x}_{\mathrm{ij}} \leq \mathrm{x}_{\mathrm{i} 0} \quad \forall \mathrm{i}$

$\sum_{\mathrm{j}} \lambda_{\mathrm{j}} \mathrm{y}_{\mathrm{k}^{\prime} \mathrm{j}} \geq \mathrm{y}_{\mathrm{k}^{\prime} 0} \quad \forall \mathrm{k}^{\prime} \neq \mathrm{k}$

$\sum_{j} \lambda_{j} y_{k j} \geq y_{k}$

$\sum_{\mathrm{j}} \lambda_{\mathrm{j}}=1$

$\lambda_{\mathrm{j}} \geq 0 \forall \mathrm{j}$

$\mathrm{y}_{\mathrm{k}} \geq 0 \quad\left(\mathrm{y}_{\mathrm{k}}\right.$ integer if $\left.\mathrm{k} \in \mathrm{O}^{\text {int }}\right)$ 
Models (9) and (10) and the maximum potential improvements (8) are analogous to those used in MEA (see, e.g., Holvad et al. 2004, Hougaard et al. 2004, Asmild et al. 2009, Asmild and Pastor 2010) and are used because they allow taking into account the differences in the margin for improvement along the different dimensions, thus creating the right spread of the directional vectors. This will be seen in the illustration shown in the next section.

Note also that (6) and (7) imply that

$$
\sum_{i} \frac{g_{i}^{\mathrm{x}}}{\mathrm{R}_{\mathrm{i} 0}^{\mathrm{x}}}+\sum_{\mathrm{k}} \frac{\mathrm{g}_{\mathrm{k}}^{\mathrm{y}}}{\mathrm{R}_{\mathrm{k} 0}^{\mathrm{y}}}=1
$$

In the above expression it must be taken into account that for some inputs and outputs the maximum potential improvement $\mathrm{R}_{0 \mathrm{i}}^{\mathrm{x}}$ and $\mathrm{R}_{0 \mathrm{k}}^{\mathrm{y}}$, respectively, may be zero, indicating that DMU is weak efficient. For those non-improvable input and output dimensions the corresponding components of the directional vector would be zero as per (7) and hence (11) should be interpreted as excluding those dimensions. It is computationally more efficient to treat those variables the same as if they were non-discretionary, so that the unit simplex (6) would not include those dimensions. This leads to a reduced number of sampling directional vectors generated for a given grid size $\Delta$.

The normalization of the directional vectors given by (11) means that the operating points corresponding to a directional stepsize $\beta=1$, i.e.

$$
\begin{aligned}
& \mathrm{x}_{\mathrm{i} 0}^{\text {grid }}=\mathrm{x}_{\mathrm{i} 0}-\mathrm{g}_{\mathrm{i}}^{\mathrm{x}} \\
& \mathrm{y}_{\mathrm{k} 0}^{\text {grid }}=\mathrm{y}_{\mathrm{k} 0}+\mathrm{g}_{\mathrm{k}}^{\mathrm{y}}
\end{aligned}
$$

are regularly distributed along the diagonal hyperplane of the hyperrectangle that has $\left(\mathrm{x}_{0}, \mathrm{y}_{0}\right)$ and the ideal point

$$
\mathrm{x}_{\mathrm{i} 0}^{\mathrm{ideal}}=\mathrm{x}_{\mathrm{i} 0}^{\min } \quad \forall \mathrm{i} \quad \mathrm{y}_{\mathrm{k} 0}^{\mathrm{ideal}}=\mathrm{y}_{\mathrm{k} 0}^{\max } \quad \forall \mathrm{k}
$$

as opposing vertices. For efficient DMUs that hyperrectangle reduces to a single point since a DMU 0 is efficient if and only if $\left(\mathrm{x}_{0}^{\text {ideal }}, \mathrm{y}_{0}^{\text {ideal }}\right)=\left(\mathrm{x}_{0}, \mathrm{y}_{0}\right), \quad$ or, equivalently, 
$\mathrm{R}_{\mathrm{i} 0}^{\mathrm{X}}=\mathrm{R}_{\mathrm{k} 0}^{\mathrm{y}}=0 \quad \forall \mathrm{i} \forall \mathrm{k}$. For efficient DMUs there is no need to sample the directional vectors. Their directional efficiency score in any improving direction is equal to 1 by definition. For an efficient DMU the directional efficiency score (4) is equal to 1 for any improving direction since an efficient DMU is always projected onto itself.

For inefficient DMUs, the maximum stepsize for each canonical directional vector $(0,0, \ldots, 1, \ldots, 0)$ is $\beta^{*}=1$. Moreover, due to the convexity of the PPS, for any directional vector computed as per (7), the corresponding operating point $\left(\mathrm{x}_{0}^{\text {grid }}, \mathrm{y}_{0}^{\text {grid }}\right)$ belongs to the PPS and, therefore, its computed maximum stepsize $\beta^{*} \geq 1$. The proposed approach can also be applied to non-convex technologies (like FDH) but in that case $\beta^{*} \geq 1$ would not necessary hold for all improving directions. $\beta^{*} \geq 0$ is guaranteed though.

Therefore, for each inefficient DMU 0, the proposed MEM approach generates multiple normalized, equally spaced $\alpha=\left(\alpha^{\mathrm{x}}, \alpha^{\mathrm{y}}\right)$ vectors, determining the corresponding directional vector $\mathrm{g}=\left(\mathrm{g}^{\mathrm{x}}, \mathrm{g}^{\mathrm{y}}\right)$ using (7), solving the corresponding DDF model (2) and computing its associated target (3) and directional efficiency score (4). In this way we obtain an estimation of the distribution of the directional efficiency scores of DMU 0 along all possible improvement directions. In the process we also collect a number of efficient targets which lie at varying distances from DMU 0. Targets corresponding to larger directional efficiency scores are closer while targets corresponding to smaller directional efficiency scores are more distant. This is an empirical way of computing the closest efficient target and it is an alternative to the existing exact methods (e.g. Aparicio et al. 2007, 2017, Aparicio 2016).

If we assume that the Decision Maker has a preference structure that assigns more weights to certain input and outputs, as given by a set of strictly positive weights $\left(\mathrm{w}_{\mathrm{i}}^{\mathrm{x}}, \mathrm{w}_{\mathrm{k}}^{\mathrm{y}}\right)$ such that $\sum_{\mathrm{i}} \mathrm{w}_{\mathrm{i}}^{\mathrm{x}}=\mathrm{m}, \sum_{\mathrm{k}} \mathrm{w}_{\mathrm{k}}^{\mathrm{y}}=\mathrm{s}$, the only modifications in the approach described above are the objective function of model (2) and the directional efficiency score (4), which would then be, respectively 
$\operatorname{Max}_{\lambda, \beta, s^{\mathrm{x}}, \mathrm{s}^{\mathrm{y}}, \hat{\mathrm{x}}, \hat{\mathrm{y}}} \beta+\varepsilon \cdot\left(\sum_{\mathrm{i}} \mathrm{w}_{\mathrm{i}}^{\mathrm{x}} \cdot \frac{\mathrm{s}_{\mathrm{i}}^{\mathrm{x}}}{\mathrm{x}_{\mathrm{i} 0}}+\sum_{\mathrm{k}} \mathrm{w}_{\mathrm{k}}^{\mathrm{y}} \cdot \frac{\mathrm{s}_{\mathrm{k}}^{\mathrm{y}}}{\mathrm{y}_{\mathrm{k} 0}}\right)$

$\eta_{0}\left(g^{\mathrm{x}}, g^{\mathrm{y}}\right)=\frac{\frac{1}{\mathrm{~m}} \cdot \sum_{\mathrm{i}} \mathrm{w}_{\mathrm{i}}^{\mathrm{x}} \cdot \frac{\hat{\mathrm{x}}_{\mathrm{i}}\left(\mathrm{g}^{\mathrm{x}}, \mathrm{g}^{\mathrm{y}}\right)}{\mathrm{x}_{\mathrm{i} 0}}}{\frac{1}{\mathrm{~s}} \cdot \sum_{\mathrm{k}} \mathrm{w}_{\mathrm{k}}^{\mathrm{y}} \cdot \frac{\hat{\mathrm{y}}_{\mathrm{k}}\left(\mathrm{g}^{\mathrm{x}}, \mathrm{g}^{\mathrm{y}}\right)}{\mathrm{y}_{\mathrm{k} 0}}}=\frac{1-\frac{1}{\mathrm{~m}} \cdot \sum_{\mathrm{i}} \mathrm{w}_{\mathrm{i}}^{\mathrm{x}} \cdot \frac{\mathrm{x}_{\mathrm{i} 0}-\hat{\mathrm{x}}_{\mathrm{i}}\left(\mathrm{g}^{\mathrm{x}}, \mathrm{g}^{\mathrm{y}}\right)}{\mathrm{x}_{\mathrm{i} 0}}}{1+\frac{1}{\mathrm{~s}} \cdot \sum_{\mathrm{k}} \mathrm{w}_{\mathrm{k}}^{\mathrm{y}} \cdot \frac{\hat{\mathrm{y}}_{\mathrm{k}}\left(\mathrm{g}^{\mathrm{x}}, \mathrm{g}^{\mathrm{y}}\right)-\mathrm{y}_{\mathrm{k} 0}}{\mathrm{y}_{\mathrm{k} 0}}}$

Note that when $\mathrm{w}_{\mathrm{i}}^{\mathrm{x}}=1 \quad \forall \mathrm{i}$ and $\mathrm{w}_{\mathrm{k}}^{\mathrm{y}}=1 \quad \forall \mathrm{k}$ the above expressions coincide with the unweighted case (2) and (4).

\section{Illustration}

Consider the numerical example shown in Table 1, which consists of nine DMUs that consume a single, constant input and produce two outputs. The two-dimensional projection of the corresponding PPS on the output subspace is shown in Figure 1.

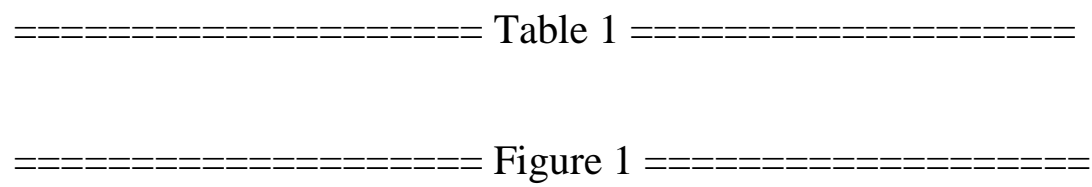

It can be seen that four DMUs, namely A, B, C and E, are efficient. As regards DMU D, which is not efficient, it can be projected onto the efficient frontier using different DEA approaches. Table 2 and Figure 1 show the corresponding efficiency score and the target computed by BCC, ERGM/SBM, RDM, MEA and BAM approaches. Note that MEA uses the ideal point of DMU D (labelled Ideal $_{D}$ in Figure 1), not to be confused with the ideal DMU (labelled Ideal DMU in Figure 1) used by RDM. Thus, the latter is common to all inefficient DMUs of the sample while the ideal point of each DMU is different and specific to that DMU. 
It can be seen that each method carries out the projection using a specific direction or criterion and thus computes a different target and a different efficiency score. In particular, it can be seen that ERGM/SBM computes the furthest target while the BCC target is the closest. The targets computed by the other three methods are relatively similar. In any case, it is clear that there are many (actually an infinite number of) potential efficient targets, some of them closer than others and each one leading to a different efficiency assessment. What the proposed MEM approach does is to recognize this fact and instead of computing a single efficiency score the whole distribution of the directional efficiency scores is estimated. This can be done using different values for the grid size $\Delta$. Figure 2 shows the projections computed for DMU D by the DDF model (2) for the different directional vectors generated using $\Delta=0.1$ and $\Delta=0.05$. The corresponding directional efficiency scores (4) are also shown. Note that, to reduce clutter, the inefficient DMUs F, G, H and I are not plotted in Figure 2. For the sake of comparison, Figure 2 also shows the projections for $\mathrm{N}=25$ random directional vectors, i.e. using a Monte Carlo method instead of our grid-based approach. Note that, for a finite sample, the random directional vectors oversample some regions and undersample others and thus are not uniformly spread, at least not as much as the grid-based directional vectors.

\section{$=$ Figure 2}

The number of directional vectors sampled in this two-dimensional example is equal to $\frac{1}{\Delta}+1$ and, hence, it is larger the smaller the value of $\Delta$. Note that, independently of the value of $\Delta$, the canonical directional vectors determine the maximum potential improvement along each dimension. Those maximum potential improvements determine the ideal point of DMU D. The arrows of the vectors shown in Figure 2 correspond to the vectors $\beta^{*} \cdot\left(g_{1}^{y}, g_{2}^{y}\right)$. The endpoints of the actual directional vectors $\left(\mathrm{g}_{1}^{\mathrm{y}}, \mathrm{g}_{2}^{\mathrm{y}}\right)$ lay on the diagonal of the rectangle defined by the maximum potential improvement projections along each output dimension. Actually, the directional vectors are equally spread on that diagonal segment. The spacing is larger (actually double) for $\Delta=0.1$ than for $\Delta=0.05$. In both cases, it can be seen that for any directional vector $\beta^{*} \geq 1$, with equality occurring always for the canonical directional vectors. 
Figure 3 shows the distribution of the directional efficiency scores computed with $\Delta=0.05$ (i.e. 21 directional vectors sampled) as well as for the Monte Carlo method using N=200 random directional vectors, which is supposed to have a more precise estimation (at the cost of approximately ten times more computational expense). The minimum, median, maximum and first and third quartiles (Q1 and Q3, respectively) of both approaches are reported in Table 2. The table also shows the targets computed for the corresponding directional vectors. In particular, in this example, the directional target associated with the MEM median coincides with the MEA target. To visualize this, a slightly larger width is used for the corresponding directional vector in Figure 2. Note also that although the directional target corresponding to the MEM median coincides with the MEA target, the MEM median does not coincide with the MEA efficiency score because the way both efficiency scores are measured is different.

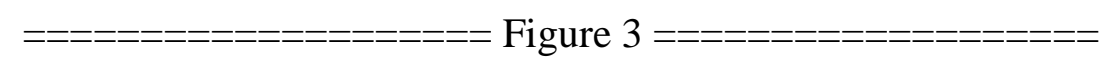

Finally, although, in order not to lengthen the paper, only the results of the assessment of DMU D have been shown, the results for the other inefficient DMUs have been included in the online supplementary material file.

\section{Case study}

This section applies the proposed MEM approach to assess the efficiency of material recovery facilities (MRFs). MRFs receive residential and commercial waste and use a combination of equipment and manual labor to separate and densify materials that are subsequently sent to processors to produce new products. No previous applications of DEA to this type of facilities exist in the literature. Two inputs have been considered: Municipal solid waste processed (Waste) and the Staff level (Labour). Waste is a non-discretionary variable and Labour an integer variable. As regards the outputs, they are the amounts recovered of each of five categories of products: Polyethylene terephthalate (PET), High density polyethylene (HDPE), Liquid packaging board (LPB), Paper/cardboard (P/C), and Steel (Steel). Table 3 shows the summary statistics of the different variables. The 36 DMUs considered correspond to the observed operating point of six MRFs over a period of six months. 
Since a non-oriented efficiency assessment is desired and given the existence of an integer variable, neither BCC nor SBM can be applied. Hence, the DMUs have been projected using BAM, MEA and RDM. The three approaches, as well as the proposed MEM approach, report that 25 of the DMUs are efficient. For each of the 11 inefficient DMUs, the directional efficiency score and corresponding target for 3,003 directional vectors (corresponding to a value $\Delta=0.1$ ) have been computed. Figure 4 shows, for each inefficient DMU, the MEM boxplot together with the values for the other three approaches. Having in mind that all these methods use different ways of measuring the distance to the efficient frontier, it can be noted that, except for DMUs 11 and 14, the efficiency scores computed by BAM, MEA and MEM are usually rather similar. Also, for most DMUs, they are much higher than MEM. DMU 31 is a notable exception. Note also that, except for DMUs 11 and 14, the MEM dispersion is not large, indicating that the maximum relative improvement in any direction does not vary much. For DMUs 11 and 14, in contrast, the maximum relative improvement is highly dependent on the improving direction chosen.

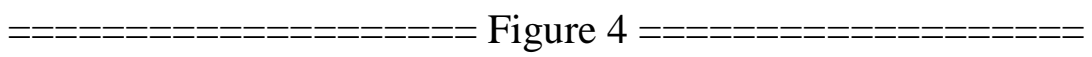

Table 4 shows the results for one of the inefficient DMUs, namely DMU 14. The tables for the other inefficient DMUs are included as supplementary material. In the case of this DMU, the range of values of MEM is relatively large, ranging from a minimum of 0.426 to a maximum of 0.664. As regards the corresponding targets, they are completely different. Although for all the methods the targets dominate the observation (i.e. they consume less input and produce more output) and the Labour target is integer, the input and output targets differ significantly, indicating that they correspond to completely different projection directions. Thus, for example, the BAM target computes a rather large input reduction and large increases of the LPB, P/C and Steel outputs. The MEA target, in turn, does not reduce Labour as much nor increases LPB, P/C and Steel as much as BAM, opting for increasing PET and HDPE more. The RDM target continues that trend, reducing Labour less than MEA and increasing LPB, P/C and Steel less than MEA and PET, and HDPE more than MEA. The MEM targets are also varied, with the target associated with the minimum efficiency score of MEM similar to the BAM target and the 
target associated with the maximum efficiency score of MEM more similar to the RDM target. The targets associated with the median, Q1 and Q3 efficiency scores of MEM represent other intermediate input and output mixes.

Finally, Figure 5 shows, for some DMUs, their corresponding MEM distribution. Similar figures for the other inefficient DMUs are included as supplementary material. Note that, for each DMU, this distribution shows how close overall the DMU is to the efficient frontier (lower overall MEM values indicating larger distance) as well as if the distance varies much or not, depending on the probing direction. Note that the shape of the MEM distribution varies from one inefficient DMU to another and it is a reflection of the geometry of the region of the efficient frontier that dominates the DMU. As opposed to the two-dimensional dataset of Section 3, in this multidimensional case the shape of the efficient frontier cannot be visualized directly but leads to a specific distribution of efficiency scores that captures and summarizes the corresponding multidimensional geometrical features.

\section{Conclusions}

This paper proposes a novel way of assessing the efficiency of the DMUs that instead of computing the distance to a single point on the efficient frontier, as existing DEA approaches do, samples that distance using multiple directional vectors. This is done using a grid-based method that generates directional vectors uniformly spread in the subspace that dominates the DMU. The result is an estimation of the distribution of the corresponding directional efficiency scores. That distribution provides information on the overall relative distance to the efficient frontier as well as on whether the distance varies much or not, depending on the improvement direction considered.

Although the main aim of the proposed MEM approach is to estimate the distribution of the directional efficiency scores, the fact is that the procedure also provides a number of efficient targets with a large variety of input-output mixes. This collection of Pareto-Koopmans efficient 
targets can be useful for selecting the most preferred target, i.e. one whose trade-offs are most satisfactory to the DMU. The proposed MEM approach can be used in the presence of nondiscretionary and integer variables. It can also incorporate preference information in the efficiency assessment.

The working of the method has been illustrated on a two-dimensional dataset as well as on a real-world case study involving municipal solid waste-processing MRFs. The proposed approach allows estimating the distribution of the efficiency, including minimum, maximum and median values, for each DMU. The shape and dispersion of the efficiency distribution differ for the different DMUs, thus providing information about the geometry of the region of the efficient frontier on which the DMU can be projected. Also, useful information about the corresponding potential targets is obtained in the process.

Although carrying out a thorough assessment of the efficiency of the DMUs instead of computing the distance to a single target on the efficient frontier has appeal, it also has larger computation costs. Thus, the smaller the grid size $\Delta$, the higher the precision of the estimated MEM distribution but also the larger the computing cost. However, since efficiency measurement is not something to be done in real time, in general it may be worth investing some computational effort in carrying out a more comprehensive and enriched assessment.

Apart from the computational expense, the main limitation of the proposed approach is the assumption that all the observed inputs and output values have to be strictly positive. Relaxing this assumption is a topic for further research as it is also how to make the approach translation invariant. Currently, due to the way the slacks are normalized in phase II of the DDF model used and the SBM-like way of computing the directional efficiency scores, the MEM approach, although units invariant, is not translation invariant. Using some translation invariant way of normalizing the slacks (using, for example, the input and output ranges or their standard deviations) may be investigated. Although it may increase the computational cost, using a lexicographic DDF method similar to the lexicographic radial approach of Korhonen et al. (2018) could be interesting. Other interesting topics for further research are extending the proposed approach to network DEA or using it in a centralized DEA context. 


\section{Acknowledgements}

This research was carried out with the financial support of the Spanish Ministry of Economy, Industry and Competitiveness and the European Regional Development Fund, grant DPI201785343-P. Narges Soltani acknowledges the support of a grant from the Ministry of Science, Research and Technology of the Islamic Republic of Iran. The authors are indebted to Mr. Luis Haro, MRF Consultant, for providing us with the MRF data. They would also like to thank the Associate Editor and two anonymous reviewers for their helpful comments and suggestions.

\section{References}

Aparicio, J., "A survey on measuring efficiency through the determination of the least distance in data envelopment analysis”, Journal of Centrum Cathedra, 9, 2 (2016) 143-167

Aparicio, J., Cordero, J.M. and Pastor, J.T., "The determination of the least distance to the strongly efficient frontier in Data Envelopment Analysis oriented models: Modelling and computational aspects", Omega, 71 (2017) 1-10

Aparicio, J., Ruíz, J.L. and Sirvent, I., "Closest targets and minimum distance to the Paretoefficient frontier in DEA”, Journal of Productivity Analysis, 28 (2007) 209-218

Asmild, M. and Pastor, J.T., Slack free MEA and RDM with comprehensive efficiency measures, Omega, 38 (2010) 475-483

Asmild, M., Holvad, T., Hougaard, J.L. and Kronborg, D., "Railway reforms: do they influence operating efficiency?", Transportation, 36, 5 (2009) 617-638

Asmild, M. and Hougaard, J.L., "On Measuring Technological Possibilities by Hypervolumes”, in: J. Aparicio, C.A.K. Lovell, J.T. Pastor (eds.), Advances in Efficiency and Productivity, Berlin, Springer (2016) 59-70

Asmild, M., Hougaard, J.L., Kronborg, D. and Kvist, H.K., "Measuring Inefficiency Via Potential Improvements”, Journal of Productivity Analysis, 19, 1 (2003) 59-76

Banker, R.D., Charnes, A. and Cooper, W.W., "Some models for estimating technical and scale inefficiencies in data envelopment analysis”, Management Science, 30, 9 (1984) 1078-1092 
Bogetoft, P., and Hougaard, J.L., "Efficiency evaluations based on potential (non-proportional) improvements", Journal of Productivity Analysis, 12, 3 (1999) 233-247

Charnes, A., Cooper, W.W. and Rhodes, E., "Measuring the efficiency of decision making units”, European Journal of Operational Research, 2, 6 (1978) 429-444

Charnes, A., Cooper, W.W., Golany, B., Seiford, L. and Stutz, J., "Foundations of data envelopment analysis for Pareto-Koopmans efficient empirical production functions", Journal of Econometrics, 30 (1985) 91-107

Chambers, R.G., Chung, Y. and Färe, R., "Benefit and Distance Functions", Journal of Economic Theory, 70 (1996) 407-419

Chen, Y., Chiu, Y. and Chiu, C., "The performance evaluation of banks considering risk: an application of undesirable relation network DEA", International Transactions in Operational Research, doi:10.1111/itor.12446

Cooper, W.W., Seiford, L.M. and Tone, K., Data Envelopment Analysis: A Comprehensive Text with Models, Applications, References and DEA-Solver Software, $2^{\text {nd }}$ edition, Springer, New York, 2006

Cooper, W.W., Pastor, J.T., Borras, F., Aparicio, J. and Pastor, D., "BAM: a bounded adjusted measure of efficiency for use with bounded additive models", Journal of Productivity Analysis, 35 (2011) 85-94

Färe, R., Grosskopf, S. and Lovell, C.A.K., The measurement of efficiency of production, Kluwer-Nijhoff, Boston, 1985

Holvad, T., Hougaard, J.L., Kronborg, D. and Kvist, H.K., "Measuring inefficiency in the Norwegian bus industry using multi-directional efficiency analysis", Transportation, 31, 3 (2004) 349-369

Hougaard, J.L., Kronborg, D. and Overgård, C., "Improvement Potential in Danish Elderly Care", Health Care Management Science, 7,3 (2004) 225-235

Hsiao, B., Shu, L. and Chou, F., "Assessing the efficiency of the accounting industry using multiactivity network DEA: evidence from Taiwan", International Transactions in Operational Research, (2017) doi:10.1111/itor.12416 
Huang, C., "Using a hybrid two-stage DEA model to analyze the profitability and marketability of medical manufacturing firms", International Transactions in Operational Research, (2018) doi:10.1111/itor.12546

Kazemi Matin, R. and Kuosmanen, T., "Theory of integer-valued data envelopment analysis under alternative returns to scale axioms", Omega, 37, 5 (2009) 988-995

Korhonen, P.J., Dehnokhalaji, A. and Nasrabadi, N., "A lexicographic radial projection onto the efficient frontier in Data Envelopment Analysis", European Journal of Operational Research, 265 (2018) 1005-1012

Kuosmanen, T. and Kazemi Matin, R., "Theory of integer-valued data envelopment analysis", European Journal of Operational Research, 192, 2 (2009) 658-667

Lozano, S. and Villa, G., "Data envelopment analysis of integer-valued inputs and outputs", Computer and Operations Research, 33, 10 (2006) 3004-3014

Moreno, P. and Lozano, S., "Super SBI Dynamic Network DEA approach to measuring efficiency in the provision of public services", International Transactions in Operational Research, 25 (2018) 715-735

Pastor, J.T., Ruiz, J.L. and Sirvent, I., "An enhanced DEA Russell graph efficiency measure", European Journal of Operational Research, 115 (1999) 596-607

Podinovski, V.V. and Bouzdine-Chameeva, T., "Solving DEA models in a single optimization stage: Can the non-Archimedean infinitesimal be replaced by a small finite epsilon?", European Journal of Operational Research, 257, 2 (2017) 412-419

Russell, R.R. and Schworm, W., "Axiomatic foundations of efficiency measurement on datagenerated technologies", Journal of Productivity Analysis, 31, 2 (2009) 77-86

Russell, R.R. and Schworm, W., "Properties of inefficiency indexes on 〈input, output〉 space", Journal of Productivity Analysis, 36, 2 (2011) 143-156

Silva Portela, M.C.A., Thanassoulis, E. and Simpson, G., "Negative data in DEA: a directional distance function approach applied to bank branches", Journal of the Operational Research Society, 55, 10 (2004) 1111-1121 
Tone, K., "A slacks-based measure of efficiency in data envelopment analysis", European Journal of Operational Research, 130, 3 (2001) 498-509

Tran, C. T. and Villano, R. A., "Measuring efficiency of Vietnamese public colleges: an application of the DEA- based dynamic network approach", International Transactions in Operational Research, 25 (2018) 683-703

Yu, M.M. and Hsiao, B., "Single- phase slack- based centralized DEA for resource reallocation", International Transactions in Operational Research, 25 (2018) 737-751 
Table 1. Illustration dataset

\begin{tabular}{|c|c|c|c|}
\hline DMU & $\mathrm{x}$ & $\mathrm{y}_{1}$ & $\mathrm{y}_{2}$ \\
\hline $\mathrm{A}$ & 10 & 10 & 50 \\
\hline B & 10 & 25 & 45 \\
\hline C & 10 & 40 & 10 \\
\hline D & 10 & 8 & 25 \\
\hline E & 10 & 35 & 30 \\
\hline F & 10 & 25 & 20 \\
\hline G & 10 & 15 & 40 \\
\hline H & 10 & 30 & 10 \\
\hline I & 10 & 20 & 15 \\
\hline
\end{tabular}


Table 2. DMU D efficiency scores and targets computed using different DEA approaches

\begin{tabular}{|c|c|c|c|c|c|}
\hline & & & & & \\
\hline & & \multirow[b]{2}{*}{ Efficiency Score } & \multicolumn{3}{|c|}{ Target } \\
\hline & & & $\mathrm{x}$ & $\mathrm{y}_{1}$ & $\mathrm{y}_{2}$ \\
\hline \multicolumn{2}{|c|}{ BAM } & 0.556 & 10 & 25.00 & 45.00 \\
\hline \multicolumn{2}{|c|}{ ERGM/SBM } & 0.359 & 10 & 35.00 & 30.00 \\
\hline \multicolumn{2}{|c|}{$\mathrm{BCC}$} & 0.519 & 10 & 15.42 & 48.19 \\
\hline \multicolumn{2}{|c|}{ RDM } & 0.377 & 10 & 27.95 & 40.58 \\
\hline \multicolumn{2}{|c|}{ MEA } & 0.364 & 10 & 27.08 & 41.88 \\
\hline \multirow{5}{*}{$\begin{array}{c}\text { MEM } \\
(\Delta=0.05)\end{array}$} & Maximum & 0.615 & 10 & 10.00 & 50.00 \\
\hline & Q3 & 0.502 & 10 & 16.59 & 47.80 \\
\hline & Median & 0.395 & 10 & 27.08 & 41.88 \\
\hline & Q1 & 0.366 & 10 & 33.35 & 32.48 \\
\hline & Minimum & 0.359 & 10 & 35.19 & 29.25 \\
\hline \multirow{5}{*}{$\begin{array}{l}\text { Monte Carlo } \\
\text { method } \\
(\mathrm{N}=200)\end{array}$} & Maximum & 0.615 & 10 & 10.03 & 49.99 \\
\hline & Q3 & 0.544 & 10 & 13.81 & 48.73 \\
\hline & Median & 0.428 & 10 & 22.75 & 45.75 \\
\hline & Q1 & 0.377 & 10 & 30.77 & 36.35 \\
\hline & Minimum & 0.359 & 10 & 35.13 & 29.46 \\
\hline
\end{tabular}


Table 3. Summary statistics of MRF dataset

\begin{tabular}{|c|c|r|c|r|r|r|c|}
\cline { 2 - 8 } \multicolumn{1}{c|}{} & \multicolumn{2}{c|}{ Inputs } & \multicolumn{5}{c|}{ Outputs } \\
\cline { 2 - 8 } \multicolumn{1}{c|}{} & Waste & Labour & PET & HDPE & LPB & P/C & Steel \\
\hline Maximum & $19,729.0$ & 90 & 242.06 & 76.50 & 222.40 & 290.22 & 291.10 \\
\hline Average & $10,933.9$ & 58.9 & 119.14 & 35.50 & 56.88 & 119.48 & 147.92 \\
\hline Minimum & $5,071.0$ & 32 & 26.07 & 5.61 & 11.04 & 22.58 & 16.52 \\
\hline Std. dev. & $4,468.8$ & 22.8 & 67.59 & 21.89 & 43.82 & 88.22 & 87.04 \\
\hline
\end{tabular}

Table 4. Observed inputs and outputs and computed efficiency scores and targets for DMU 14

\begin{tabular}{|c|c|c|c|c|c|c|c|c|c|}
\hline & \multirow{2}{*}{$\begin{array}{l}\text { Eff. } \\
\text { Score }\end{array}$} & \multicolumn{2}{|c|}{ Inputs } & \multicolumn{5}{|c|}{ Outputs } \\
\hline & & & Waste & Labour & PET & HDPE & LPB & $\mathrm{P} / \mathrm{C}$ & Steel \\
\hline \multicolumn{2}{|c|}{ Observation } & - & 11,790 & 84 & 187.36 & 29.74 & 121.96 & 190.04 & 85.36 \\
\hline \multicolumn{2}{|c|}{ BAM } & 0.519 & 11,790 & 56 & 187.36 & 40.90 & 186.38 & 275.89 & 211.43 \\
\hline \multicolumn{2}{|c|}{ MEA } & 0.655 & 11,790 & 68 & 192.62 & 46.80 & 154.80 & 232.98 & 197.45 \\
\hline \multicolumn{2}{|c|}{ RDM } & 0.718 & 11,790 & 74 & 195.53 & 50.05 & 136.96 & 217.54 & 186.58 \\
\hline \multirow{5}{*}{$\begin{array}{c}\text { MEM } \\
(\Delta=0.1)\end{array}$} & Maximum & 0.664 & 11,790 & 78 & 197.93 & 52.72 & 121.96 & 211.61 & 175.06 \\
\hline & Q3 & 0.564 & 11,790 & 68 & 187.36 & 52.20 & 125.25 & 247.26 & 178.76 \\
\hline & Median & 0.513 & 11,790 & 65 & 187.36 & 44.42 & 167.32 & 206.65 & 220.98 \\
\hline & Q1 & 0.467 & 11,790 & 61 & 187.36 & 41.89 & 184.22 & 229.09 & 226.27 \\
\hline & Minimum & 0.426 & 11,790 & 56 & 187.36 & 40.90 & 186.44 & 274.35 & 212.01 \\
\hline
\end{tabular}




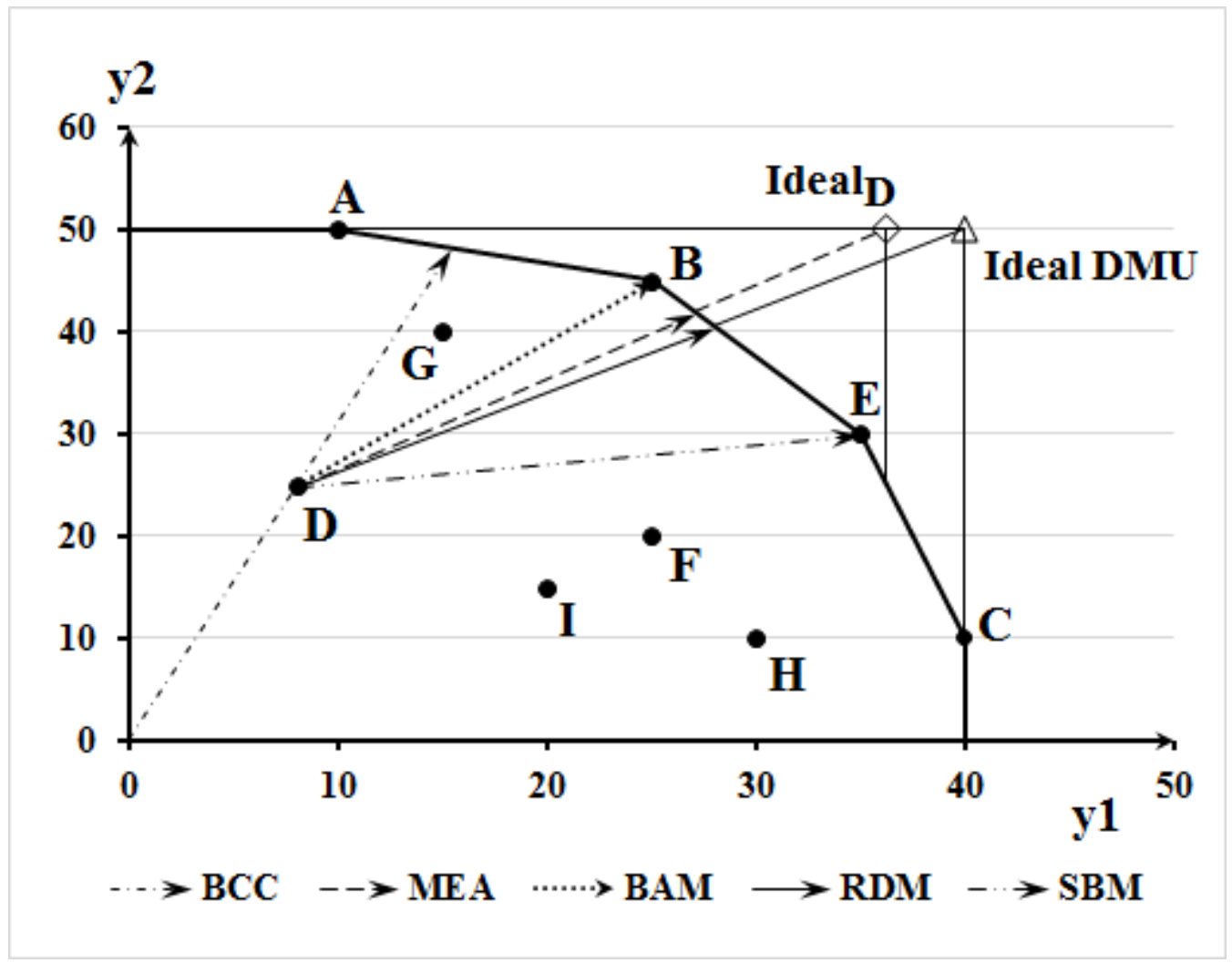

Figure 1. Projections of DMU D computed using different DEA approaches 

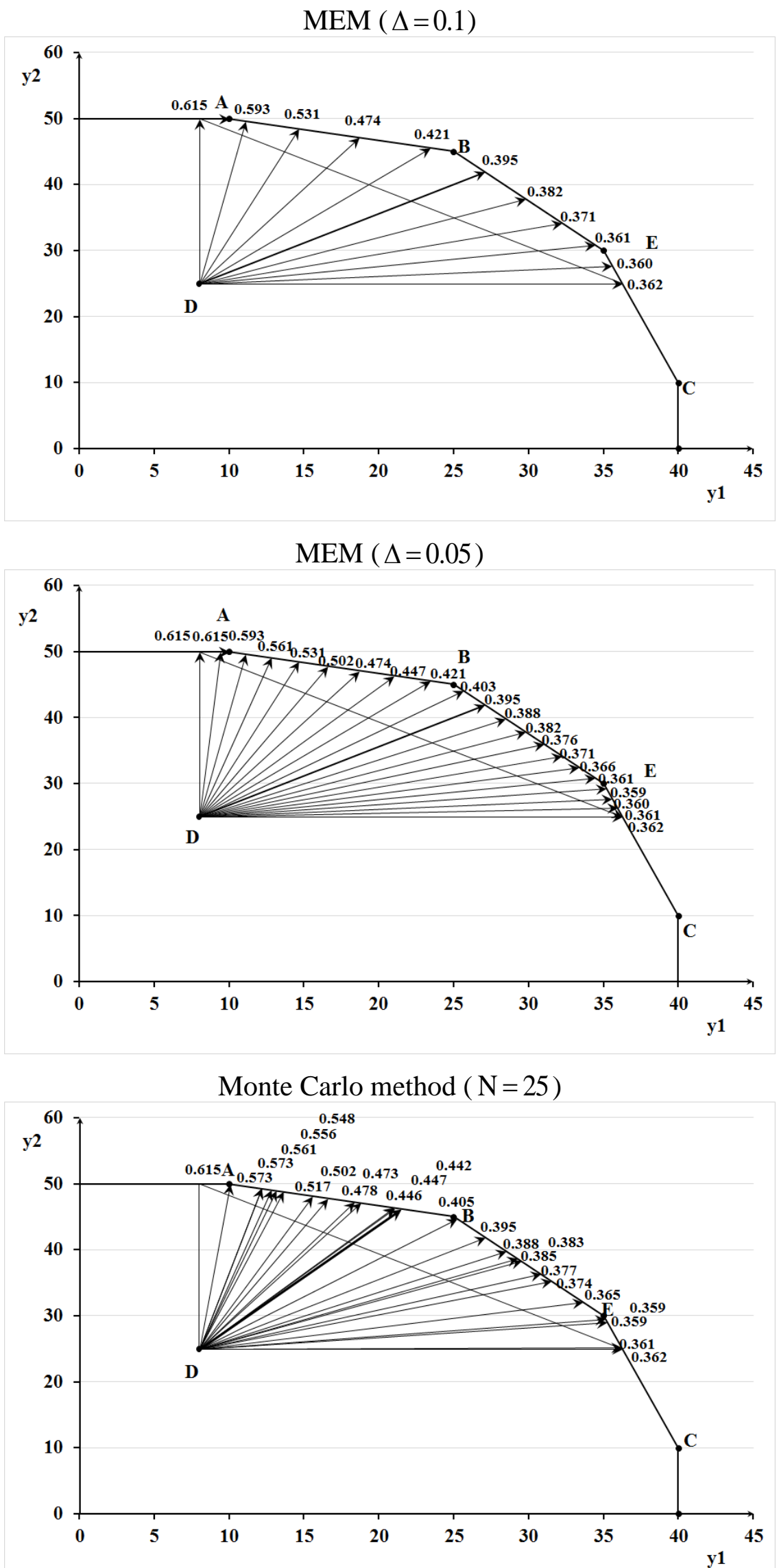

Figure 2. Results of MEM ( $\Delta=0.1$ and $\Delta=0.05)$ and Monte Carlo method $(\mathrm{N}=25)$ 

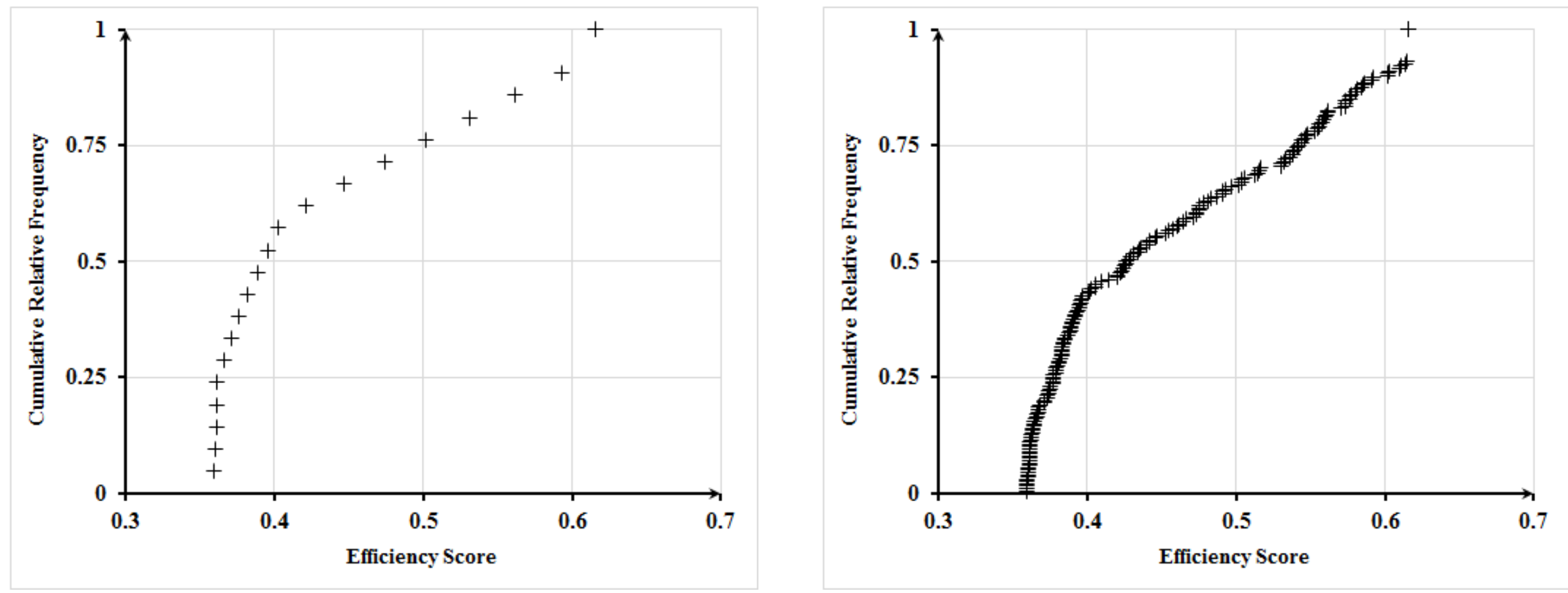

Figure 3. Distribution of MEM ( $\Delta=0.05$, left panel) and Monte Carlo method ( $\mathrm{N}=25$, right panel) 


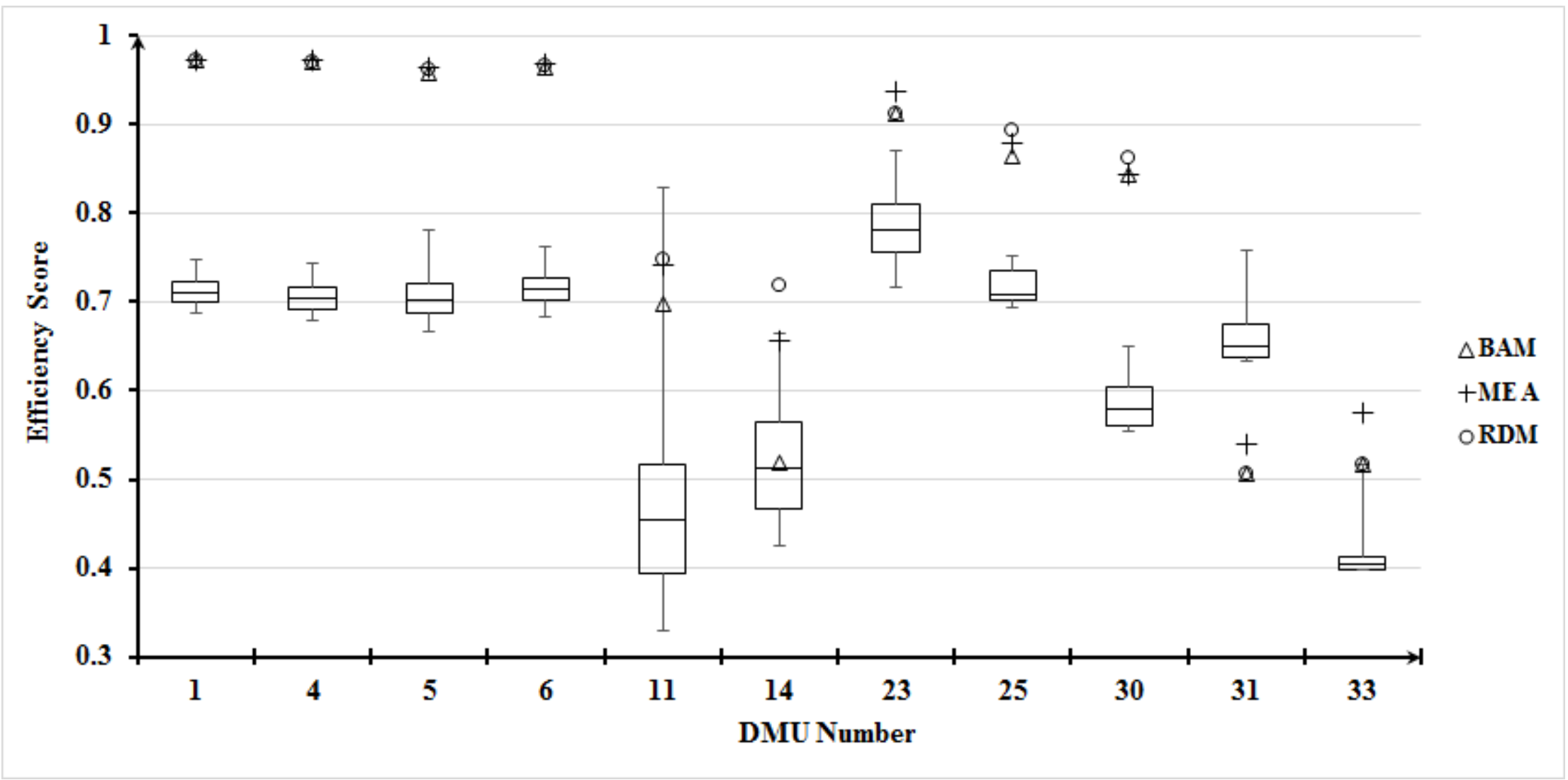

Figure 4. BAM, MEA and RDM efficiency scores and boxplots of MEM $(\Delta=0.1)$ 
DMU 5

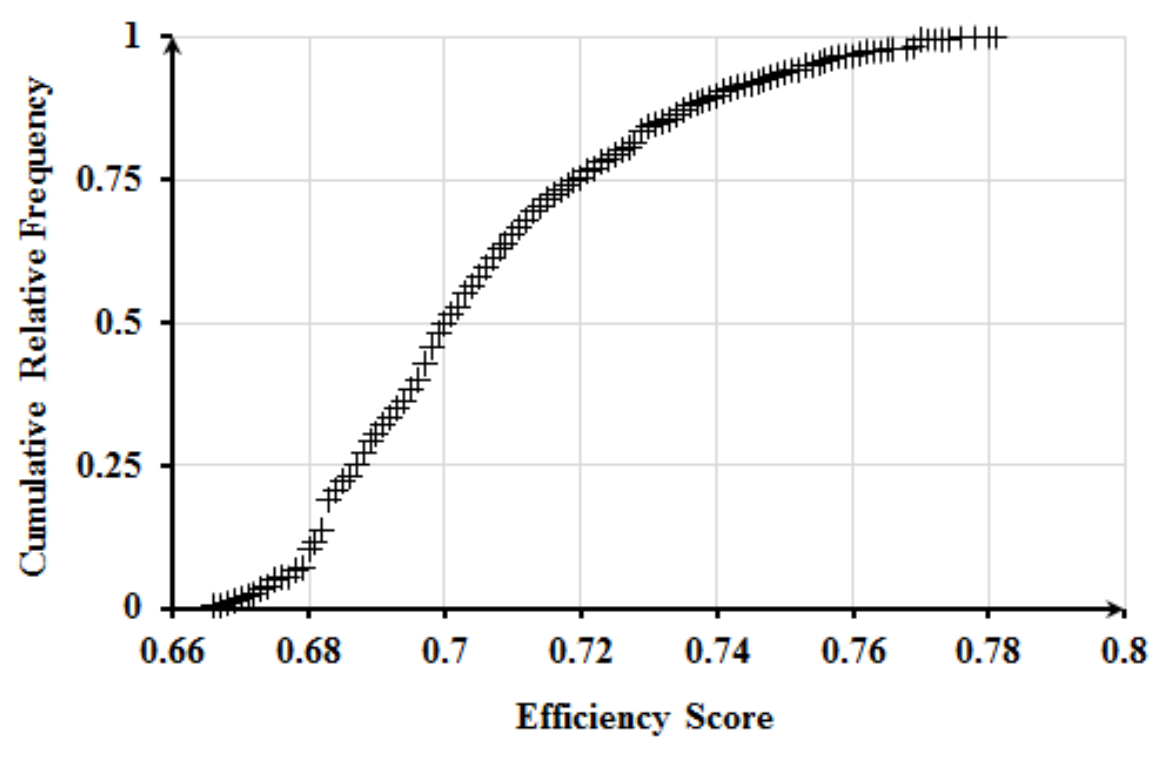

DMU 14

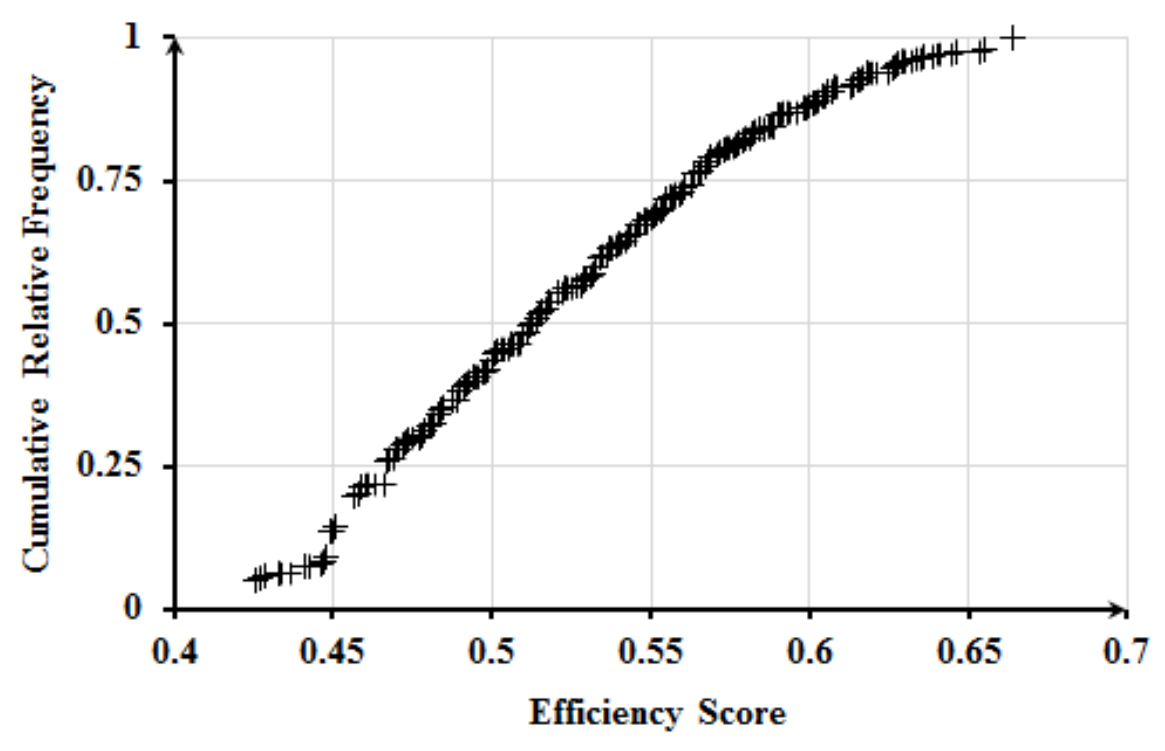

DMU 11

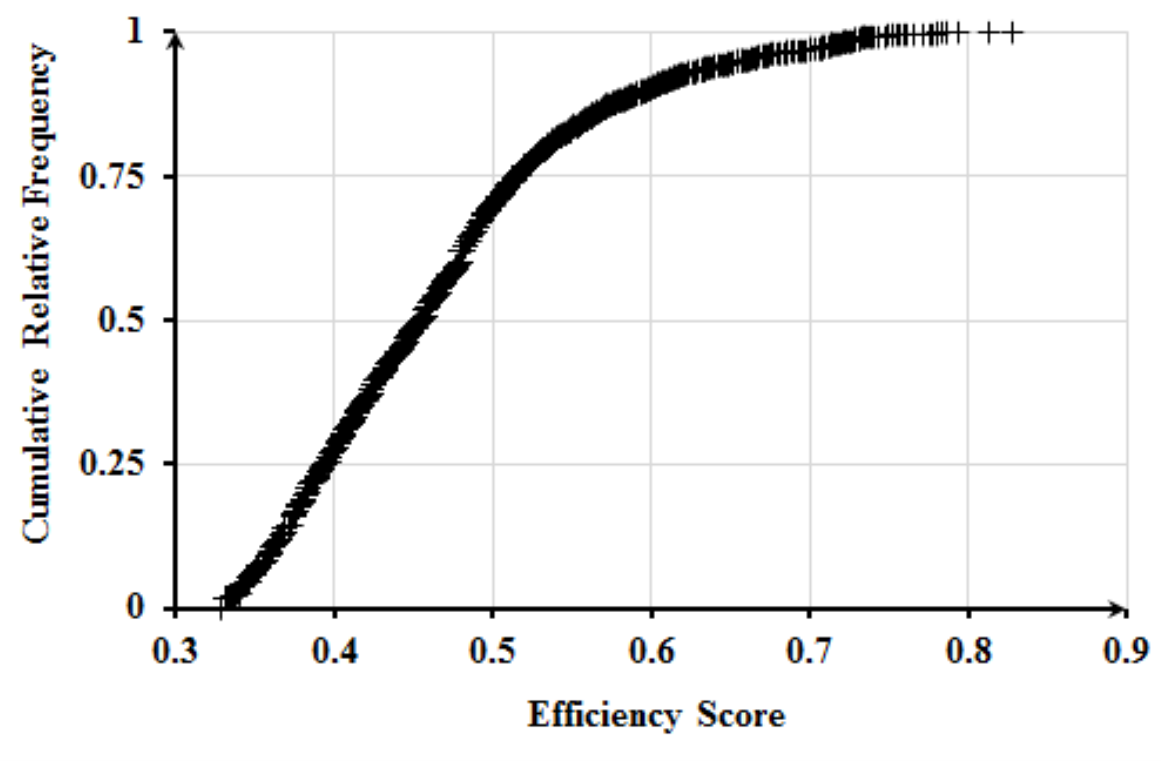

DMU 23

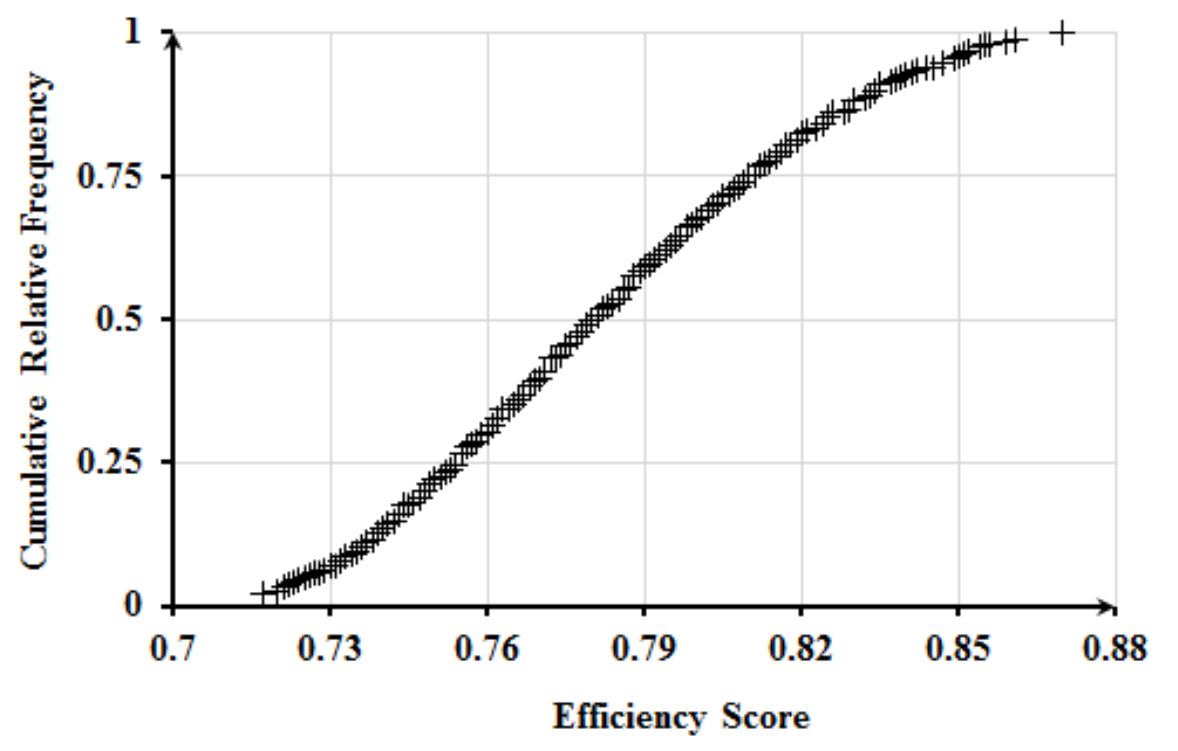

Figure 5. Distribution of MEM ( $\Delta=0.1)$ for some inefficient DMUs 